\title{
Health seeking behaviour in management of erectile dysfunction among men in an urban African population
}

\author{
Olajide O. Abiola ${ }^{1 *}$, Oluwaseyi J. Adigun², \\ Olushola J. Ajamu ${ }^{3}$, Oyeronke T. Williams ${ }^{4}$
}

\author{
${ }^{1}$ Department of Surgery, Bowen University Teaching Hospital, Ogbomoso, Nigeria \\ ${ }^{2}$ Department of Health Education and Health Promotion, University of Ilorin, Ilorin, Nigeria \\ ${ }^{3}$ Department of Surgery, Lautech University Teaching Hospital, Ogbomoso, Nigeria \\ ${ }^{4}$ Department of Internal Medicine, Obafemi Awolowo University Teaching Hospital, Ile-Ife, Nigeria
}

Received: 04 December 2017

Accepted: 30 December 2017

\author{
*Correspondence: \\ Dr. Olajide O. Abiola, \\ E-mail: sooabiola2015@gmail.com
}

Copyright: (c) the author(s), publisher and licensee Medip Academy. This is an open-access article distributed under the terms of the Creative Commons Attribution Non-Commercial License, which permits unrestricted non-commercial use, distribution, and reproduction in any medium, provided the original work is properly cited.

\begin{abstract}
Background: Erectile dysfunction (ED) is consistent inability to achieve/maintain penile erection sufficiently enough for satisfactory sexual intercourse. It is a major sexual disorder causing significant distress in men with associated poor quality of life. Despite it being a common sexual disorder, many of the affected people do not seek medical care. The study sought to investigate health seeking behaviour in management of ED among urban dwelling African men.

Methods: A cross-sectional descriptive survey method was adopted. The study population comprised of men drawn from an urban setting in Nigeria using a multi-stage sampling technique. Three hypotheses were formulated which were cultural beliefs, financial status and medical access/perception on quality of care will not significantly influence health seeking behaviour for management of ED. Researchers' designed questionnaire validated by three experts drawn from the relevant fields with reliability co-efficient of 0.77 obtained through split half method by Pearson product moment correlation was used for data collection. The three postulated hypotheses were tested using Person product moment correlation.

Results: All the three hypotheses were rejected at 0.05 alpha level of significance because their calculated $r$-values were greater than their critical values.

Conclusions: It was concluded that cultural beliefs, financial status and access to medical facilities/perception of quality of care from such medical facilities influence the health seeking behaviour of men in the management of ED.
\end{abstract}

Keywords: African population, Erectile dysfunction, Health seeking behaviour

\section{INTRODUCTION}

Sexuality is a central aspect of human being throughout life and encompasses sex, gender identities and roles, sexual orientation, eroticism, pleasure, intimacy and reproduction. ${ }^{1}$ One of sexual disorders which have an impact on sexuality is erectile dysfunction (ED) which was defined by National Institute of Health (NIH) as consistent inability to maintain a penile erection, sufficiently for satisfactory sexual intercourse. ${ }^{2}$ It impairs good sexual function which had been shown to be a high priority for men and their partners throughout their life span with loss of sexual harmony found to reduce the sexual satisfaction and quality of life of men and their partners. ${ }^{3,4}$

In an African country-Nigeria, prevalence of erectile dysfunction ranges from $43.8 \%$ in a community based study to $57.4 \%$ among men attending primary care 
clinics. ${ }^{5,6}$ However, its true burden may be difficult to ascertain in that many men suffering from ED find it difficult to discuss sexual issues freely with people including their spouse and physicians. ${ }^{7,8}$

In Nigeria, despite the burden of this disorder, there is a low patronage of health care professionals for the management of this condition as most men with ED do not seek any form of treatment while those who do, mostly resort to herbal remedies. ${ }^{8,9}$ Thus, there is poor health seeking behaviour for management of ED among Nigerian men. Erectile dysfunction is a disorder associated with a lot of misconceptions among Nigerian men and a man's perception of erectile dysfunction also affects his helpseeking behaviour. ${ }^{11}$ Such misconceptions/perceptions of ED with other factors such as socio-cultural, socioeconomic status, cost of health care, access to medical care and perceived quality of care/health professional attitudes can influence the populace's health seeking behaviour. ${ }^{12,13}$

Thus, the study sought to investigate the influence of cultural belief, financial status and medical access/perception of quality of care on health seeking behaviour for ED management among men in an urban African population using a study population from Nigeria. Such information on health seeking behaviour in management of ED may help in policy formulation in sexual health system and treatment protocol development.

\section{METHODS}

This was a descriptive cross-sectional epidemiological study conducted in a multi-cultural urban African population community-Ogbomoso in South-west, Nigeria. Ogbomoso town is made up of two local government areas of Oyo state consisting of ten wards in each of the local government area. It has an estimated population of 645,000 (2006 National census). ${ }^{14}$ Majority of the people are of Yoruba ethnic group but other major tribes such as Hausa and Igbo equally reside in the town. The three prominent Nigerian religions (Christianity, Islam and traditional religion) are been practiced by the inhabitants of the community.

The sample size for this study was determined using the formula:

$\mathrm{n}=\mathrm{Z}^{2} \times \mathrm{p}(1-\mathrm{p}) / \mathrm{d}^{2}$

where,

$\mathrm{n}$ : required sample size;

$Z$ : confidence level at $95 \%$ (standard value of 1.96 );

p: expected proportion of ED based on previous study;

$\mathrm{d}$ : margin of error at $5 \%$ (standard value of 0.05 ).

Based on previous study with a prevalence of $43.8 \%$ of ED in a community in South west Nigeria which has as similar socio-demographics as the proposed study population. ${ }^{5}$ Initial estimated sample size was 378 . However, with an envisaged response rate of $90 \%$ based on the response rate in an earlier pilot study in the community, the final estimated sample size was 420 determined with the formula:

$\mathrm{nf}=\mathrm{N} /$ percentage response rate

where,

nf = final sample size,

$\mathrm{N}=$ initial sample size.

\section{Sampling method}

A multi-stage sampling technique was adopted in which five wards were selected through simple random technique from each of the two local government areas that made up Ogbomoso town. Each selected wards were divided into clusters using the streets in each ward.

Two clusters were selected from the list of clusters in each ward by balloting. Purposive sampling technique was used to select four hundred and twenty (420) men above 18 years who are sexually active residing in all houses of the selected clusters. The study was explained to each respondent and only those who gave their consent participated in the study.

\section{Research instrument}

The instrument for data collection was a researchers' structured questionnaire of 9-items consisting of 3 questions each on influence of cultural beliefs, financial status and medical access/quality of care on health seeking behaviour for management of ED in the respondents. Responses were graded on a five-point Likert scale.

The instrument was validated by the three experts from the relevant fields. The reliability of the instrument was carried out through the split half method using Pearson Product Moment Correlation (PPMC) and correlation coefficient of 0.77 was obtained which was considered reliable to carry out the study.

The instrument was administered with the help of three trained research assistants and on spot collection was made to attain high retrieval rate.

\section{Inclusion criteria}

Men who were 18 years and above, sexually active and gave consents to participate in the study were involved in the study.

\section{Exclusion criteria}

Men who are less than 18years or not sexually active or decline participation in the study were exempted from the study. 


\section{Ethical consideration}

Ethical approval to embark on this study was sought from the Ethical Review Committee of Bowen University Teaching Hospital, Ogbomoso. Consents were obtained from study participants and those who failed to give their consents were excluded from the study.

Participation was entirely voluntary and respondents who were found to have erectile dysfunction were counselled and appropriately referred to Urology clinic of Bowen University Teaching Hospital for expert care.

\section{Research hypotheses}

The following research hypotheses were tested to guide the study.

- Cultural beliefs will not significantly influence health seeking behavior in management of ED among urban dwelling men.

- Financial status will not significantly influence health seeking behavior in management of ED among urban dwelling men.

- Medical access and perception on quality of care will not significantly influence health seeking behavior in management of ED among urban dwelling men.
- The hypotheses were tested using Pearson Product Moment Correlation at 0.05 alpha level of significance.

\section{RESULTS}

Four hundred and twenty (420) respondents completed the questionnaire with an age range of 25 to $75 y$ ears and a mean age of $56 \pm 2.4$ years.

Majority of the respondents $(82.2 \%)$ were married, while $17.8 \%$ were single and sexually active.

\section{Hypotheses testing}

\section{Hypothesis 1}

Cultural beliefs will not significantly influence health seeking behaviour in management of ED among urban dwelling men.

The Pearson Product Moment Correlation (PPMC) Analysis of influence of cultural beliefs on health seeking behavior of respondents in management of ED revealed a calculated r-value of 0.556 greater than the critical value of 0.098 ; hence, the null hypothesis was rejected (Table 1).

Table 1: Pearson Product Moment Correlation analysis of influence of cultural beliefs on health seeking behavior in management of erectile dysfunction among urban dwelling African men.

\begin{tabular}{|lll|lllll|}
\hline Variable & $\mathbf{N}$ & $\overline{\mathbf{x}}$ & SD & Df & Calculated r-value & Critical value & Decision \\
\hline $\begin{array}{l}\text { Health seeking } \\
\text { behavior for ED }\end{array}$ & 420 & 27.433 & 2.371 & 418 & 0.556 & 0.098 & $\begin{array}{l}\text { Hypothesis } \\
\text { rejected }\end{array}$ \\
\hline Cultural beliefs & 420 & 9.233 & 1.342 & & & & \\
\hline
\end{tabular}

* ED: Erectile dysfunction

Table 2: Pearson Product Moment Correlation analysis of influence of financial status on health seeking behavior in management of erectile dysfunction among urban dwelling African men.

\begin{tabular}{|lllllll|l|}
\hline Variable & $\mathbf{N}$ & $\overline{\mathbf{x}}$ & SD & Df & Calculated r-value & Critical value & Decision \\
\hline $\begin{array}{l}\text { Health seeking } \\
\text { behavior for ED }\end{array}$ & 420 & 420 & 27.433 & 2.371 & 0.824 & 0.098 & $\begin{array}{l}\text { Hypothesis } \\
\text { rejected }\end{array}$ \\
\hline Financial status & 420 & 9.891 & 1.062 & & & & \\
\hline
\end{tabular}

* ED: Erectile dysfunction

This implied that cultural beliefs may significantly influence health seeking behaviour of urban dwelling men in management of ED.

\section{Hypothesis 2}

Financial status will not significantly influence health seeking behaviour in management of ED among urban dwelling men.
Findings from the Person Product Moment Correlation Analysis of influence of financial status on health seeking behaviour of the respondents in management of ED are depicted in Table 2.

With the calculated r-value of 0.824 greater than the critical value of 0.098 , the null hypothesis was rejected. It implied that financial status may significantly influence health seeking behaviour of urban dwelling men in management of ED. 


\section{Hypothesis 3}

Medical access and perception on quality of care will not significantly influence health seeking behaviour in management of ED among urban dwelling men.
The Person Product Moment Correlation Analysis of influence of medical access and perception on quality of care on health seeking behaviour of the respondents in management of ED as seen in Table 3 revealed a calculated r-value of 0.621 and a critical value of 0.098 at 0.05 alpha level of significance.

Table 3: Pearson Product Moment Correlation analysis of influence of medical access and perception on quality of care on health seeking behavior in management of erectile dysfunction among urban dwelling African men.

\begin{tabular}{|c|c|c|c|c|c|c|c|}
\hline Variable & $\mathbf{N}$ & $\overline{\mathbf{x}}$ & SD & Df & Calculated $\mathrm{r}$ - value & Critical value & Decision \\
\hline $\begin{array}{l}\text { Health seeking } \\
\text { behavior for ED }\end{array}$ & 420 & 420 & 27.433 & 2.371 & 0.621 & 0.098 & $\begin{array}{l}\text { Hypothesis } \\
\text { rejected }\end{array}$ \\
\hline $\begin{array}{l}\text { Medical access and } \\
\text { perception of } \\
\text { quality of care }\end{array}$ & 420 & 8.309 & 1.206 & & & & \\
\hline
\end{tabular}

The null hypothesis was rejected as the calculated r-value of 0.621 was greater than the critical value of 0.098 . Therefore, ability to access medical facilities and perceived quality of care from medical facilities may dictate health seeking health behaviour of urban dwelling men in management of ED.

\section{DISCUSSION}

The findings from this study show that cultural beliefs of the respondents will influence their desire to seek help in managing erectile dysfunction. It was established from previous studies that, perception on health issues influences an individual desire to seek medical attention and such perceptions on health issues could be influenced by cultural beliefs and practices in the society. ${ }^{15-18}$ This could be further justified by an observation by Wah yun in a multicultural society in which she reported that cultural beliefs and practices in the society influences the populace perception of health and illness; and more specifically, the influence of a man's perception of erectile dysfunction on his help-seeking behaviour. ${ }^{11}$

Culture/cultural beliefs, sexual dysfunction and desire for medical attention are intricably interwoven with each other as justified in an earlier study by Mehmet et al with a report of increasing empirical evidence of relationship between culture, sexual dysfunction and sex therapy. ${ }^{19}$

The finding from the tested hypothesis two showed that financial status played a significant role in influencing the desire of the respondents to seek medical attention for erectile dysfunction.

In Africa with a report from Nigeria, treatment options of ED were traditional (phytotherapy, zootherapy and occultism) and non-traditional (orthodox practice- drug therapy, psychological and behavioural counseling) therapy. ${ }^{20}$ The cost of each choice varied considerably and the poor who are financially constrained are often restricted to limited choice. ${ }^{21}$ Also, there is a significant difference in access to various health care providers between the rich and poor as observed by Nabyonga et al in a study from Uganda. ${ }^{22}$ Furthermore, financial status of an individual apart from influencing the choice of treatment, it may also influence the desire to seek medical advice; an assertion corroborated by Dillip et al who observed that inadequate financial resources usually contribute to delay in accessing medical facilities. ${ }^{23}$

From earlier studies in Nigeria, it was observed that most men with ED do not seek any form of treatment while those who do, mostly resort to herbal remedies which may be related to preference for herbal remedies among the populace which are presumed to be safe, effective and beneficial. ${ }^{8,9,24}$

Accessibility to medical facilities and perception of quality of care from such facilities influences the respondents' desire to seek medical attention for management of ED.

It is established from previous studies in Nigeria that patronage of medical facilities for management of ED is low among men. ${ }^{8-10}$ Takure et al, observed a possible missing link between the high community incidences of ED of $41.5 \%$ to $57.4 \%$ in Nigeria and low hospital patronage of about $2 \%$ despite the acceptable outcome of treatment for ED among men who presented to the hospital. ${ }^{25,5,6,26}$ Such possible missing link may be related to accessibility of health facilities equipped for management of sexual dysfunction and perception of quality of care from such facilities.

In Nigeria, access to specialist physicians are often in the tertiary teaching hospital; conversely, only few people in the population had the means to access such tertiary health institution..$^{28,29}$

A study by Ariba et al observed that primary care physicians usually have the first contact with patients with ED; and many of the physicians would not take sexual history unless patient brought it up. ${ }^{9}$ Such poor physician- 
patients' interaction on sexual disorder/therapy may be due inadequate knowledge and experience of physicians in managing the ailment, lack of a standardized protocol to manage the sexual disorder and social stigma associated with discussion of sexual problems. ${ }^{9}$

Perception of quality of care for an ailment in health facilities is often influenced by individual's perception of the aetiology of the ailment and socio-cultural factors. This so because the community's culture and values direct the pattern of illness and health care.$^{30}$ Erectile dysfunction is associated with a lot of misconceptions by Nigerian men; some believe it is a reward for promiscuity or spiritual affliction. ${ }^{10,26}$ With such misconceptions, it is not unexpected if an individual with such misconceptions do not seek medical attention for his ailment. In Nigeria, its being reported the many men with ED do not seek any form of treatment while those who do, mostly resort to herbal remedies; a consequence of cultural perception on aetiology and the perceived better response to use of indigenous herbs. ${ }^{8,26,27}$

\section{CONCLUSION}

Based on the findings from the analyses of the tested hypotheses, the following conclusions were drawn:

- Cultural beliefs about ED significantly influenced the health seeking behaviour of men with ED.

- Financial status of men with ED significantly influenced their health seeking behaviour in its management.

- Medical access and perception of quality of care for ED significantly influenced health seeking behaviour in its management.

\section{Recommendations}

In view of the findings in this study, the following recommendations were made:

- Advocacy on the aetiology and possible management of ED among the populace to improve their knowledge and disabuse the long held cultural beliefs about ED.

- Improvement in health care access, financing/health insurance and inclusion of sexual health as a component of primary health care so as to improve health care access and affordability of management of ED.

- Development of standardized protocol in management of ED and training of physicians to improve sexual health care delivery and patient-physicians' relationship in discussing sexual related problems.

Funding: No funding sources

Conflict of interest: None declared

Ethical approval: The study was approved by the Institutional Ethics Committee

\section{REFERENCES}

1. World Health Organization. Sexual and reproductive health. 2016. Available at www.who.in/reproductivehealth/topics/sexual_health /sh_definitions/en/. Accessed 10 March 2017.

2. National Institute of Health (NIH) consensus development panel on impotence. JAMA. 1993;270(1):83-90.

3. Dunn ME. Restoration of couple's intimacy and relationship vital to re-establishing erectile function. $\mathbf{J}$ Am Osteopath. 2004;104(3):6-10.

4. Balon R. Sexual dysfunction. The brain-body connection. Adv Psychosom Med Basel. 2008;29:1-6.

5. Olugbenga-Bello AI, Adeoye AO, Adeomi AA, Olajide AO. Prevalence of erectile dysfunction and its risk factors among adult men in a Nigerian community. Nigeria Postgraduate Med J. 2013;20(2):130-5.

6. Shaeer KZ, Osegbe DN, Siddiqui SH, Razzaque A, Glasser DB, Jaguste V. Prevalence of erectile dysfunction and its correlated among men attending primary care clinics in three countries: Pakistan, Egypt and Nigeria. Int J Impotence Res. 2003;15(1):814.

7. Okwonkwo JEN, Uwakwe R, Obionu C, Okonkwo $\mathrm{CV}$. Communication and sexuality in a Nigerian community. Advances in Conception. 2010;15(1):618 .

8. Omisanjo O, Faboya O, Aleetan O, Babatune A, Taiwo A, Ikuerowo S. Prevalence and treatment pattern of erectile dysfunction amongst men in Southwestern Nigeria. Int J Sexual Med. 2014;3(1):14.

9. Ariba AJ, Oladopo OT, Iyaniwura CA, Dada OA. Management of erectile of dysfunction: perception and practices of Nigerian primary care clinicians. SA Fam Pract. 2007;49(9):16-29.

10. Yovwin DG, Imarhiagbe FA, Obazee EM, Oguike TC. Erectile dysfunction in a sub-saharan African population: profile and correlates in a tertiary care hospital. Sahel Med J. 2015;18:116-20.

11. Wah-Yun L. Malaysian cultural differences in knowledge, attitudes and practices related to erectile dysfunction. Available at www.sexualhealthvisual.com. Accessed 24 October 2016.

12. Shaikh BT, Hatcher J. Health seeking behaviour and health service utilization in Pakistan: challenging the policy makers. J Pub Health. 2004;27(1):49-54.

13. Moreira jr ED, Brock G, Glasser DB, Nicolosi A, Laumann EO, Paik A. Help-seeking behaviour for sexual problems: the global study of sexual attitudes and behaviors. Int J Clin Pract. 2005;59(1):6-16.

14. Federal republic of Nigeria: 2006 Population Census. Available at www.nigerianstat.gov.ng. Accessed 19 March 2017.

15. Vaughn LM, Jacquez F, Baker CB. Cultural health attributions, beliefs, and practices: effects on 
healthcare and medical education. Open Med Education J. 2009;2:64-74.

16. Nayak MG, Sharada, Geroge A. Socio-cultural perspectives on health and illness. Nitte University $\mathbf{J}$ Health Sci. 2012;2(3):61-7.

17. Mc Laughlin L, Brun K. Asian and pacific islanders cultural values: considerations for health care decision-making. Health and Work. 1998;23(2):11626

18. Ojua TA, Ishor DG, Ndom PF. African cultural practices and health implications for Nigeria rural development. Int Rev Management Business Res. 2013;2(1):176-83.

19. Mehmet ZSS, Yasin B. Cultural factors in the treatment of sexual dysfunction in Muslim clients. Current Sexual Health Rep. 2016;8(2):57-63.

20. Afolayan JA, Yakubu MT. Erectile dysfunction management options in Nigeria. J Sexual Med. 2009;6(4):1090-102.

21. Kiwanuka S, Ekirapa E, Peterson S, Okui O, Rahman $\mathrm{MH}$, Peters D. Access to and utilization of health services for the poor in Uganda. A systematic review of available evidence. Trans Research Society Tropical Med. 2008;102(111):1067-74.

22. Nabyonga J, Desmet M, Karamagi H, Kadama PY, Omaswa FG, Walker O. Abolition of cost-sharing is pro-poor: evidence from Uganda. Health Policy Plan 2005;20(2):100-8.

23. Dillip A, Alba S, Mshana R, Hetzel MW, Lengeler C. Acceptability: a neglected dimension of access to health care: findings from a study on childhood convulsions in rural Tanzania. BMC Health Service Res. 2012;12:113.

24. Oreagba IA, Oshikoya KA, Amachree M. Herbal medicine use among urban residents in Lagos,
Nigeria. BMC Complimentary Alternative Med. 2011;11:117. Available at http://www.biomedcentral.com/1472-6882/11/117

25. Takure AO, Adebayo SA, Okeke LI, Olaopa OEO, Shittu OB. Erectile dysfunction among men attending surgical outpatients Department in a Tertiary Hospital in South-Western Nigeria. Nigeria J Surg. 2016;22(1):32-6.

26. Idung A, Abasiubong F, Ukott I, Udoh S, Unadike B. Prevalence and risk factors of erectile dysfunction in Niger delta region, Nigeria. Afr Health Sci. 2012;12(2):160-5.

27. Okoh J, Okafor I, Kokonne E, Ajeh I, Isimi C, Olayemi O, et al. Popularity and customer preferences for herbal medicines in Nigeria: a questionnaire based study. Humanities Social Sciences Letters. 2016;4(3):69-76.

28. Oyedeji R, Abimbola S. How tertiary hospitals can strengthen primary health care in Nigeria. Nigerian Med J. 2014;55(6):519-20.

29. Okpani A, Abimbola S. Operationalizing universal health coverage in Nigeria through social health insurance. Nig Med J. 2015;56(5):305-10.

30. Rumun AJ. The socio-cultural patterns of illness and health care in Nigeria. Eu J Hum Social Sci. 2014;30(1):1588-98.

Cite this article as: Abiola OO, Adigun OJ, Ajamu OJ, Williams OT. Health seeking behaviour in management of erectile dysfunction among men in an urban African population. Int J Reprod Contracept Obstet Gynecol 2018;7:380-5. 